\title{
Herbal Industry Wastes as Potential Materials for Biofuel Production ${ }^{+}$
}

\author{
Aneta Sienkiewicz ${ }^{1, *}$, Alicja Piotrowska-Niczyporuk ${ }^{2}$ and Andrzej Bajguz ${ }^{2}$ \\ 1 Department of Agri-Food Engineering and Environmental Management, Bialystok University of \\ Technology, Wiejska 45E Street, 15-351 Bialystok, Poland \\ 2 Department of Biology and Plant Ecology, Ciołkowskiego 1J Street, 15-245 Bialystok, Poland; \\ alicjap@uwb.edu.pl (A.P.-N.); abajguz@uwb.edu.pl (A.B.) \\ * Correspondence: a.sienkiewicz@pb.edu.pl; Tel.: +48-(85)-746-96-52 \\ + Presented at the 9th Innovations-Sustainability-Modernity-Openness Conference (ISMO'20), \\ Bialystok, Poland, 20-21 May 2020.
}

Published: 15 July 2020

\begin{abstract}
Due to the increasing awareness of the depletion of fossil fuel resources and environmental issues, biodiesel as alternative fuel has become more and more attractive in the recent years. In this research, the characterization of herbal industry wastes as a potential feedstock for biodiesel production was carried out. There results of analytical identification of the fatty acid methyl esters (FAME) obtained in the transesterification reaction are presented. The reaction conditions were optimized, considering hexane ratio and catalyst concentration (methanol and $\mathrm{KOH})$ for both steps. The FAME were extracted from the herbal samples by ultrasound-assisted extraction and subsequently were identified by gas chromatography-mass spectrometry (GC-MS) using single ion monitoring (SIM) method. Additionally, the selected properties of some bioesters were analyzed. This study determined the compounds which are ideal for fuel production. The unsaturated fatty acids were found in higher amounts than saturated fatty acids. Linoleic acid (C18:2n6c) was the major unsaturated fatty acid in herbal wastes, while palmitic acid (16:0) was the major saturated fatty acid. The application of the optimized method also revealed differences in the physical and chemical properties of isolated FAME mixtures compared to conventional diesel fuel. In this research work, for the first time, the possibilities of using the herbal industry wastes as a potential feedstock for biodiesel production are assessed.
\end{abstract}

Keywords: postproduction plant wastes; transesterification; FAME; renewable energy; biodiesel

\section{Introduction}

In the recent years, biodiesel production is one of the interesting alternative fuel which can be produced from renewable sources [1]. Conventional biodiesel mainly comes from soybean and vegetable oils [2], palm oil [3], sunflower oil [4], rapeseed oil [5] as well as restaurant waste oil [6]. One of the ways is the production of liquid fuel from herbal industry wastes. They are generated in the herbal production process, mainly during packing herbs. In Poland, there are many modern herbal companies, and some of them produce annually approximately 30 tons of fine wastes biomass in the form of above-ground parts of the selected species of herbs [7]. The herbal industry wastes are currently used in the biogas [8] and pellet or briquette production [9], bioconversion into vermicompost [10] and food waste composting [11]. The aim of the research was to determine the fatty acid methyl esters (FAME) from herbal industry wastes. The analyzed FAME were extracted and synthesized through the optimized transesterification reaction. During the experiment, we also determined the selected physicochemical properties of pure FAME mixtures and their potential utility as a material source for biodiesel production. 


\section{Materials and Methods}

\subsection{General}

All chemicals used for transesterification reaction were of analytical grade and were purchased from Avantor Performance Materials (Gliwice, Poland). The solvents used for GC-MS analyses were of HPLC grade from Merck (Darmstadt, Germany). The FAME mixture (Supelco 37 Component FAME Mix) was bought from Merck.

\subsection{Transesterification Reaction}

Samples (16 species of herbs) used in the experiment were obtained from herbal industries and they were in dried powder form. Plant material $(0.5 \mathrm{~g})$ was extracted with $0.5 \mathrm{~mL}$ of hexane (purity $99 \%)$ in the presence of $1 \%$ methanol-potassium hydroxide mixture $(2 \mathrm{~mL})$ as a catalyst. The extraction was assisted by an ultrasonic cleaning bath (Sonorex Digital 10P, Germany). The optimized extraction conditions were: Temperature $80{ }^{\circ} \mathrm{C}$, time $60 \mathrm{~min}$, power $10 \times 10 \%$. These reaction conditions were optimized according to the experimental design. The synthesis was conducted by the addition of $1 \mathrm{~mL}$ of hexane (purity $99 \%$ ).

\subsection{Analysis of Samples}

The FAME were identified by a gas chromatograph (7890B GC System) with a mass selective detector MSD5977A (Agilent Technologies, Santa Clara, CA, USA) using single ion monitoring (SIM) method. This device was fitted with a HP-88 capillary column $(100 \mathrm{~m} \times 0.25 \mathrm{~mm}, 0.20 \mu \mathrm{m}, 5$ in cag). Three replicates were performed for each sample. The selected properties (density, viscosity, kinematic viscosity, flash point, acid value, saponification value, moisture content, ash content, iodine value, free fatty acidic, melting point) of three samples with the highest concentration of isolated FAME mixture were also determined in terms of biofuel production.

\section{Results and Discussion}

The dominant fatty acids were palmitic acid (16:0), palmitoleic acid (16:1), oleic acid (18:1), linolelaidic acid (C18:2n6t), linoleic acid (C18:2n6c), linolenic acid (18:3), behenic acid (22:0) and nervonic acid (24:1), which are suitable for fuel production. Among them, C16:0 and C18:1 are the most ideal components of biodiesel. The total content of C16:0 in analyzed samples is greater than in castor [12], rapeseed and sunflower oils [13] (Table 1). The results also showed that the unsaturated fatty acid amount was greater than that of saturated fatty acids. The highest concentration of FAME was determined in rye bran (Secale cereale L.) $(71.42 \mathrm{mg} / \mathrm{g} \mathrm{dw})$ (Figure 1), tea "Figure" (Senna alexandrina Miller) $(23.49 \mathrm{mg} / \mathrm{g} \mathrm{dw}$ ) and roots of chicory (Cichorium intybus L.) (17.65 mg/g dw). The analysis of these samples revealed differences in the physical and chemical characteristics, compared to conventional diesel fuel.

Table 1. Fatty acid profile of herbal wastes and comparison with other biodiesel oils.

\begin{tabular}{ccccc}
\hline Oil & Herbal wastes & Castor [12] & Rapeseed [13] & Sunflower [13] \\
\hline Fatty acid profile, $\%$ & & & & \\
C16:0 palmitic & 5.04 & 1.30 & 4.92 & 4.88 \\
C18:0 stearic & 0.73 & 1.22 & 1.63 & 4.78 \\
C18:1 oleic & 4.13 & 3.61 & 66.59 & 67.66 \\
C18:2 linoleic & 9.30 & 4.58 & 17.08 & 21.26 \\
C18:3 linolenic & 3.22 & 0.39 & 7.75 & 0.09 \\
\hline
\end{tabular}




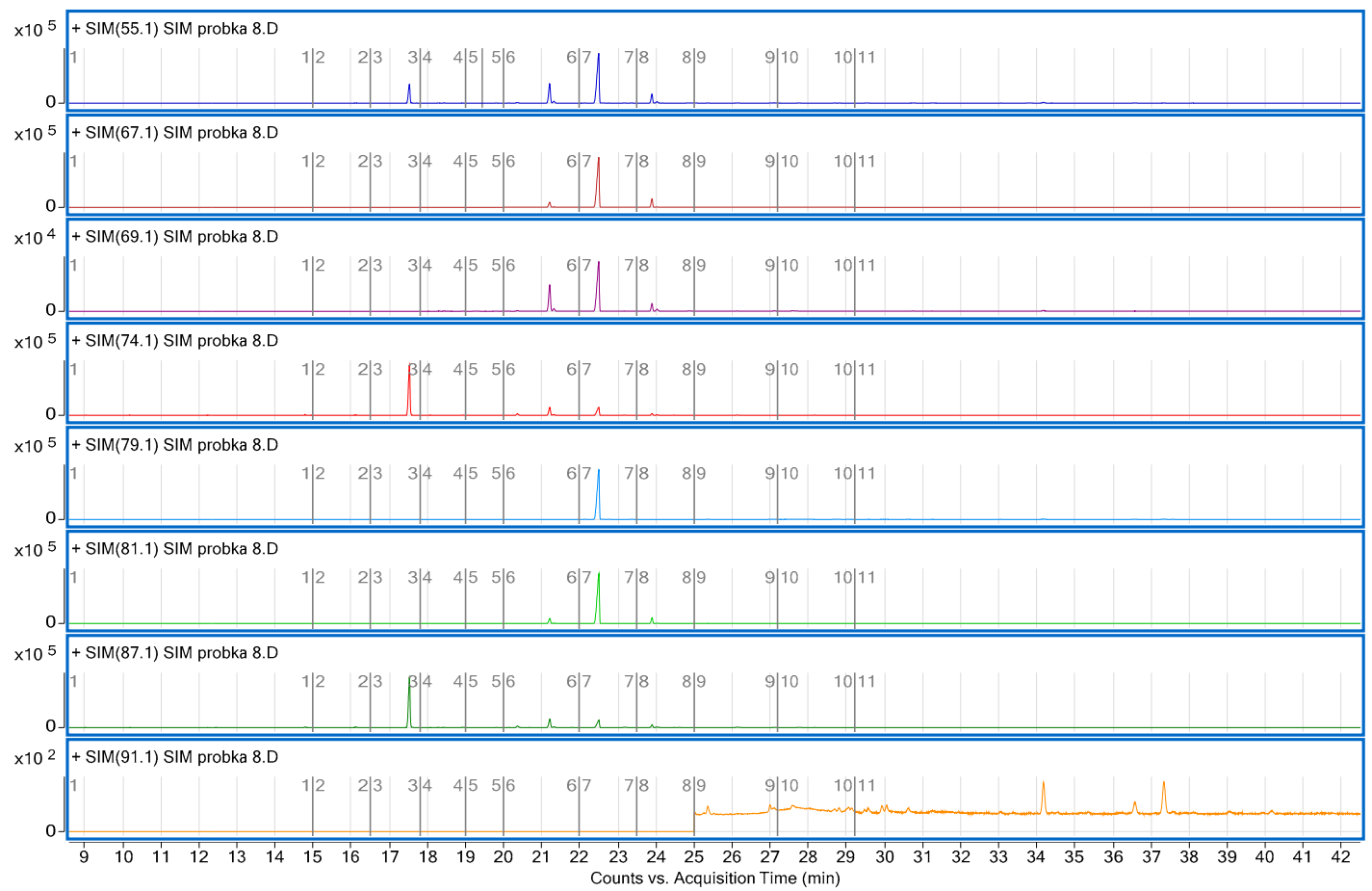

Figure 1. Chromatogram (SIM/GCMS mode) for herbal sample with the highest concentration of FAME.

\section{Conclusions}

In conclusion, the study showed that presented conditions of transesterification reaction could be used as an efficient technology for the biodiesel production from herbal industry wastes. The process was simple and generated a diverse range of FAME mixture with potential utility for biofuel production.

Author Contributions: A.S. conceived and designed the experiments; A.S. and A.P.-N. performed the experiments; A.P.-N. and A.B. analyzed the data; A.S. and A.P.-N. contributed reagents/materials/analysis tools; A.S. and A.P.-N. wrote the paper. All authors have read and agreed to the published version of the manuscript.

Acknowledgments: The authors are grateful for financial support from the National Science Centre of Poland (2019/03/X/ST8/00794) and project financed by the Ministry of Science and Higher Education of Poland no. WZ/WB-IIS/2/2020.

Conflicts of Interest: The authors declare no conflict of interest.

\section{References}

1. Helwani, Z.; Othman, M.R.; Aziz, N.; Fernando, W.J.N.; Kim, J. Technologies for production of biodiesel focusing on green catalytic techniques: A review. Fuel Process. Technol. 2009, 90, 1502-1514, doi:10.1016/j.fuproc.2009.07.016.

2. Bunyakiat, K.; Makmee, S.; Sawangkeaw, R.; Ngamprasertsith, S. Continuous production of biodiesel via transesterification from vegetable oils in supercritical methanol. Energy Fuels 2006, 20, 812-817, doi:10.1021/ef050329b.

3. Nahian, M.R.; Islam, M.N.; Khan, S.M. Production of biodiesel from palm oil and performance test with diesel in CI engine. In Proceedings of the International Conference on Mechanical, Industrial and Energy Engineering, Khulna, Bangladesh, 26-27 December 2016.

4. Antolín, G.; Tinaut, F.V.; Briceño, Y.; Castaño, V.; Pérez, C.; Ramírez, A.I. Optimisation of biodiesel production by sunflower oil transesterification. Bioresour. Technol. 2002, 83, 111-114, doi:10.1016/S0960-8524(01)00200-0. 
5. Dworakowska, S.; Bednarz, S.; Bogdal, D. Production of biodiesel from rapeseed oil. In Proceedings of the 1st World Sustainability Forum, Basel, Switzerland, 1-30 November 2011.

6. Canakci, M. The potential of restaurant waste lipids as biodiesel feedstocks. Bioresour. Technol. 2007, 98, 183-190, doi:10.1016/j.biortech.2005.11.022.

7. Obidziński, S. Charakterystyka aktywności wody i parametrów geometrycznych odpadów melisy w aspekcie ich wykorzystania jako dodatku do pasz. Acta Agrophysics 2013, 20, 113-124.

8. Lewicki, A.; Pilarski, K.; Janczak, D.; Czekała, W.; Rodríguez Carmona, P.C.; Cieślik, M.; Witaszek, K. The biogas production from herbs and waste from herbal industry. J. Agric. Eng. Res. 2013, 58, 114-117.

9. Obidziński, S. Pelletization process of postproduction plant waste. Int. Agrophysics 2012, 26, 279-284.

10. Kumari, M.; Kumar, S.; Chauhan, R.S.; Ravikanth, K. Bioconversion of herbal industry waste into vermicompost using an epigeic earthworm Eudrilus Eugeniae. Waste Manag. Res. 2011, 29, 1205-1212, doi:10.1177/0734242X10384432.

11. Zhou, Y.; Selvam, A.; Wong, J.W.C. Chinese medicinal herbal residues as a bulking agent for food waste composting. Bioresour. Technol. 2018, 249, 182-188, doi:10.1016/j.biortech.2017.09.212.

12. Sánchez, N.; Encinar, J.M.; Nogales, S.; González, J.F. Biodiesel production from castor oil by two-step catalytic transesterification: Optimization of the process and economic assessment. Catalysts 2019, 9, 864, doi:10.3390/catal9100864.

13. Martínez, G.; Sánchez, N.; Encinar, J.M.; González, J.F. Fuel properties of biodiesel from vegetable oils and oil mixtures. Influence of methyl esters distribution. Biomass Bioenergy 2014, 63, 22-32, doi:10.1016/j.biombioe.2014.01.034.

(C) 2020 by the authors. Licensee MDPI, Basel, Switzerland. This article is an open access article distributed under the terms and conditions of the Creative Commons Attribution (CC BY) license (http://creativecommons.org/licenses/by/4.0/). 